\title{
Effects of chronic fluoranthene exposure on sibling species of Capitella with different development modes
}

\author{
Inez Linke-Gamenick ${ }^{1, *}$, Valery E. Forbes ${ }^{1}$, Nuria Méndez ${ }^{2}$ \\ ${ }^{1}$ Department of Life Sciences and Chemistry, Roskilde University, PO Box 260, 4000 Roskilde, Denmark \\ ${ }^{2}$ Laboratorio de Invertebrados Bentónicos, Estación Mazatlán, Instituto de Ciencias del Mar y Limnología, UNAM, \\ Apartado Postal 811, Mazatlán, 82000 Sinaloa, Mexico
}

\begin{abstract}
Toxic effects of the polycyclic aromatic hydrocarbon fluoranthene (FLU) on life-history traits and their demographic consequences were investigated in 3 non-interbreeding Capitella sibling species with different physiological tolerances and developmental modes: sensitive Capitella sp. $\mathrm{S}$ from oxygen-rich intertidal sediments of the North Sea (Germany); tolerant Capitella sp. M from sediments near shallow hydrothermal vents off Milos (Greece), a habitat low in organic matter with steep abiotic gradients and high sulfide concentrations; tolerant Capitella sp. I from New York (USA), known to dominate eutrophicated/polluted environments. Both Capitella spp. M and I can develop into hermaphrodites and have lecithotrophic larval development. In contrast, Capitella sp. S appears to be dioecious and has direct development with benthic juveniles. In life-table-response experiments (LTRE), juveniles from the 3 species were raised under different FLU concentrations (0 to $95 \mu \mathrm{g}$ $\left.\mathrm{g}^{-1} \mathrm{FLU}\right)$, and data on age-specific survival, growth and life-history parameters were recorded at weekly intervals. Under control conditions, the 3 Capitella species differed markedly in a number of life-history traits and population growth rates $(\lambda)$, with Capitella sp. S showing the lowest $\lambda(1.05)$, and Capitella sp. M the highest (1.42). Chronic exposure to inreasing FLU concentrations also revealed species-specific differences in individual- and population-level toxic responses. Highest FLU concentrations (95 $\left.\mathrm{\mu g} \mathrm{g}^{-1}\right)$ markedly reduced juvenile survival and completely inhibited reproduction in Capitella sp. S, whereas individual life-history traits in Capitella spp. M and I were affected little, if at all. At the population level, the highest FLU exposures resulted in $\lambda$ values of effectively zero in Capitella sp. S, whereas $\lambda$ of Capitella spp. $\mathrm{M}$ and I remained $>1$. In conclusion, the combination of opportunistic life-history features, reproductive flexibility, and physiological adaptations enables Capitella spp. $\mathrm{M}$ and I to colonize habitats rapidly after local disturbance and to persist in stressed and unpredictable environments; whereas in Capitella sp. S, population extinction under toxicant stress mainly results from its physiological sensitivity.
\end{abstract}

KEY WORDS: Capitella sibling species complex $\cdot$ Fluoranthene $\cdot$ Life-history traits $\cdot$ Benthic and lecithotrophic development $\cdot$ Population growth rate

\section{INTRODUCTION}

Life-table-response experiments (LTRE) provide information on age-specific survival, growth, and fecundity in individuals raised under controlled laboratory conditions that can be translated to the population level by calculating population growth rate $(\lambda)$.

*E-mail: ipklinke@aol.com
This experimental approach is a powerful tool in analysing the responses of life-history variables to pollutants and can be used to explore demographic consequences of sublethal toxic effects on populations (e.g., Levin et al. 1987, 1996, Caswell 1989, 1996, Forbes \& Calow 1999). $\lambda$ expresses the population multiplication rate per unit time; in an increasing population $\lambda$ is $>1$, in a constant size population $\lambda=1$, in a declining population $\lambda$ is $<1$. Toxic effects may include 
reduced growth, increased mortality, delayed reproduction, and reduced reproductive output, leading to declines in $\lambda$ or even population extinction. Changes in $\lambda$ in response to changes in individual life-history traits depend on the life-history of the study organism, the severity of the toxic effect on each individual trait, as well as on the sensitivity of $\lambda$ to changes in the lifehistory traits contributing to it (e.g., Levin et al. 1987, 1996, Caswell 1989, Kammenga et al. 1996, Hansen et al. 1999). Recent studies have shown the importance of density-dependendence (i.e., food limitation) that may compensate or exacerbate negative toxic effects on population dynamics, and have suggested that density-dependence should be incorporated into LTRE analyses (Grant 1998, Linke-Gamenick et al. 1999, Sibly 1999).

The polychaete species complex Capitella capitata is widely used as a pollution indicator, because it dominates the benthic communities of organically enriched or polluted marine sediments, where it can reach extremely high population densities (e.g. Grassle \& Grassle 1974, 1976, Pearson \& Rosenberg 1978, Méndez et al. 1997). C. capitata plays an important role in improving physicochemical properties of polluted sediments through its bioturbating activities (Gardner et al. 1979, Chareonpanich et al. 1993, 1994, Madsen et al. 1997). C. capitata represents a cryptic species complex, in which adult morphology is so similar among species that no effort has been made to separate this complex with proper taxonomical species-descriptions. Nevertheless, the so-called Capitella sibling species are reproductively isolated and differ substantially in a host of other parameters, e.g., in karyotypes and enzyme patterns (Grassle \& Grassle 1976, Grassle et al. 1987, Wu et al. 1991), in ultrastructure of eggs and ovarian follicle cells, in larval, genital spine and sperm morphology (Eckelbarger \& Grassle 1983, 1987), in ecophysiological characteristics (Gamenick et al. 1998b), in sediment-processing rates (Méndez et al. unpubl. data), and in reproductive features. For several cooccurring Capitella species of the North American East Coast, Grassle \& Grassle (1976) described differences in numbers of larvae per brood, in egg size, in larval dispersal mode, and in the occurrence of hermaphrodites. Capitella sibling species also show differences in larval mode, i.e., planktotrophic, lecithotrophic, and benthic development, depending on the larval stage hatching from the maternal brood tube (Grassle et al. 1987). These differences have been further explored by Méndez et al. (unpubl. data) to include Capitella species from other geographical regions.

One of the best known species of the complex is the opportunistic Capitella sp. I (Grassle \& Grassle 1974, 1976). It has lecithotrophic development, and reproduces via dispersing larvae with high survivorship that mature rapidly after settlement. Hence, this species exhibits rapid population explosions following local disturbances. From LTRE, Bridges et al. (1994) and Levin et al. (1996) concluded that Capitella sp. I's successful persistence in disturbed and oil-polluted habitats may result to a large extent from demographic adaptations, i.e., reduced age at first reproduction and increased fecundity under eutrophic conditions. In terms of physiological mechanisms, Forbes et al. (1994) stated that the physiology of Capitella sp. I is welladapted to exploit low oxygen, high food conditions. Gamenick et al. (1998b) confirmed effective metabolic regulation of this species under stressed conditions, i.e., hypoxia and sulfide. For the first time, these authors compared several species of the Capitella complex, and found that Capitella sp. S originating from oxygen-rich low-sulfide habitats (Gamenick \& Giere 1994) has no such regulatory abilities (i.e., is an oxyconformer) and displays significantly lower survival rates under hypoxia and sulfide. Interspecific physiological differences were also found in response to xenobiotic toxicants, i.e., the polycyclic aromatic hydrocarbon fluoranthene (FLU), which is common in oil-polluted sediments (Linke-Gamenick et al. 2000). Capitella sp. I was found to be physiologically the best adapted, and showed the highest survival rates, whereas Capitella sp. S increased its metabolic rate and simultaneously reduced its food intake, resulting in high mortality rates. Morphologically the 2 species are indistinguishable, but they differ markedly in reproductive and larval modes. Capitella sp. S matures into females and males and hatches benthic juveniles that emerge from the parental brood tube after metamorphosis (= direct development) in low numbers of 16 to 50 (Gamenick \& Giere 1994, Méndez et al. unpubl. data). Capitella sp. I develops into females, males and hermaphrodites, and reproduces via free-swimming metatrochophore larvae (= lecithotrophic development) with up to 220 larvae per brood (Grassle \& Grassle 1976, Méndez et al. unpubl. data).

In this study, we used these 2 species as examples of different life-history types and physiological tolerances, and compared the effects of toxic stress (i.e., exposure to sublethal FLU concentrations) on several life-history parameters, and their demographic consequences. For comparison, we included an additional species with lecithotrophic development, Capitella sp. M (Gamenick et al. 1998a,b).

The purpose of this study was to determine whether Capitella species that differ in physiological tolerance and life-history features achieve similar $\lambda$ under uniform conditions. Are life-cycle variables of a physiologically sensitive species necessarily more impaired under toxic stress, and what are the implications for its population dynamics? Knowing that Capitella species 
vary physiologically and with respect to their life-history, another objective was to determine the relative importance of physiological adaptation versus lifehistory strategies in explaining demographic effects of toxic stress.

\section{MATERIALS AND METHODS}

Capitella spp. Three previously identified, noninterbreeding sibling species from different geographical regions and habitat types were used in this study: Capitella sp. S (Gamenick \& Giere 1994), from intertidal sediments of the Island of Sylt, North Sea, Germany; Capitella sp. M (Gamenick et al. 1998a) obtained from shallow hydrothermal vent areas in the Mediterranean Sea (Milos, Greece), an unpredictable environment characterized by steep gradients of temperature, salinity and $\mathrm{pH}$ and high sulfide concentrations (Dando et al. 1995, Thiermann et al. 1997); Capitella sp. I (Grassle \& Grassle 1976), originally obtained from Setauket Harbor, New York, USA. These species reproduce readily in culture, and have been reared under identical conditions in our laboratory for many generations.

Worms were cultured in aquaria $(20 \times 30 \mathrm{~cm})$ containing a 2 to $4 \mathrm{~cm}$ layer of azoic (i.e., frozen to $-80^{\circ} \mathrm{C}$ twice) natural sediment (grain size of $<250 \mu \mathrm{m}$ ) and aerated seawater $(32 \% \mathrm{~S})$ at $16^{\circ} \mathrm{C}$. The organic content of the sediment on which the worms were cultured was kept high by weekly additions of a 1:1:1 mixture of commercial fish-food flakes $\left(\operatorname{Tetramin}^{\odot}\right)$, baby cereal $\left(\right.$ Beauvais $\left.^{\odot}\right)$, and dried spinach (Forbes et al. 1996). Approximately $1 \mathrm{wk}$ prior to the start of the experiment, several brood tubes from each species were transferred to dishes with a small amount of sediment and seawater and checked daily for larvae for use in the experiment.

Sediment. For the experiment, we used sieved $(<63 \mu \mathrm{m})$, pre-frozen (to $-80^{\circ} \mathrm{C}$ for several weeks) sediment from Roskilde Fjord (Denmark) with a water content of $67.79 \pm 0.43 \%$ and an organic content of $6.62 \pm 1.30 \%(\mathrm{n}=6)$. FLU sediment was prepared in 6 nominal concentrations: 0 [= control] $, 5,10,20,40$ and $80 \mathrm{ug} \mathrm{g}^{-1}$ dry wt sediment $\left(=\mu \mathrm{g} \mathrm{g}^{-1}\right)$. A known volume of FLU stock solution (crystalline FLU [98\% GC grade, Aldrich] in acetone carrier) was added to a known volume of thawed sediment in a glass flask that was subsequently shaken overnight (18 h) at room temperature. Nominal FLU concentrations were estimated by accounting for water content of the sediment. The sediment was homogenized and portioned ( $2 \mathrm{~g}$ portions). Sediment samples for FLU analysis were taken (see below), and the sediment was stored frozen $\left(-20^{\circ} \mathrm{C}\right)$ until use in the experiment.
Experimental design. A total of 180 Capitella sp. S, 156 Capitella sp. M, and 144 Capitella sp. I juveniles ( 3 to $6 \mathrm{~d}$ old) were taken from the brood tubes and, for each species, randomly assigned to 6 FLU treatment groups (30 Capitella sp. S per group, 26 Capitella sp. M per group, and 24 Capitella sp. I per group). Each group was transferred into a petri dish containing $4 \mathrm{~g}$ of experimental sediment (with nominal concentrations of $0,5,10,20,40$, and $80 \mu \mathrm{g} \mathrm{g}^{-1}$ FLU, respectively) and $7 \mathrm{ml}$ seawater $(30 \% \mathrm{~S})$. The sediment and overlying seawater were $0.5 \mathrm{~cm}$ in height to enhance oxygen diffusion and prevent anoxia in the sediment. The 18 dishes were placed in a moisture chamber to reduce evaporation and kept in the dark at $18^{\circ} \mathrm{C}$. The salinity was controlled every few days.

When juveniles became sexually mature (female $=$ appearance of ovaries; male = appearance of genital spines), a female and a male were paired and transferred to new separate experimental dishes (= replicate pairs of worms per FLU concentration, i.e., up to 9 pairs), each with $2 \mathrm{~g}$ of experimental sediment and seawater, as described above. All dishes were monitored once a week for 175 d (Capitella sp. S), 133 d (Capitella sp. M), and $161 \mathrm{~d}$ (Capitella sp. I). On each census day, worms were removed from the sediment. The remaining sediment (pellets, tubes, mucus) was fixed in $75 \%$ ethyl alcohol, and data on worm survivorship, body size, wet weight, and reproduction were recorded. Worms were returned to their corresponding treatments with new experimental sediment and seawater. The following life-table parameters were estimated: age-specific survival, body volume over time until sexual maturity (= last measurement), juvenile specific growth rate (SGR), age at maturity, age at first reproduction (appearance of brood tubes), percentage of reproducing females/hermaphrodites, numbers of broods per female/hermaphrodite, age-specific fecundity, numbers of offspring per brood, time between broods, $\lambda$, and size-specific sediment processing rate (SSPR, feeding rate). Age at sexual maturity was distinguished from age at first reproduction in order to test whether FLU influenced the fraction of worms reaching maturity as well as the fraction of mature worms that actually reproduced.

FLU extraction and analysis. To measure FLU concentrations in the experimental sediments, 4 replicate sediment samples $(0.5 \mathrm{~g})$ were taken from each nominal FLU concentration and extracted with methanol and ethylacetate as described by Linke-Gamenick et al. (1999). Subsequently samples were processed and analyzed by HPLC (Kelley et al. 1993, LinkeGamenick et al. 1999).

Data analysis. For each species, the body volume of randomly chosen individuals was measured at the start of the experiment $(n=10)$ and subsequently every 2 wk $(\mathrm{n}=5)$ for each FLU treatment, until worms 
reached the mature stage. Individual worms were videotaped with a camera connected to a dissecting microscope. Body length $(L)$ and area $(A)$ were measured (3 replicates per individual) using an imageanalysis software program (Sigma Scan Pro, Jandel Inc., Erkrath, Germany). Worm body-volume ( $V$ ) calculations were based on Forbes et al. (1994):

$$
V=\pi A^{2} / 4 L
$$

Juvenile SGR until maturity was estimated as

$$
\mathrm{SGR}=\left(\ln S_{2}-\ln S_{1}\right) /\left(t_{2}-t_{1}\right)
$$

where $S_{1}$ and $S_{2}$ are body volumes at times $t_{1}$ (start) and $t_{2}$ (maturity) in days, giving the proportion grown per day.

Age-specific fecundity $\left(m_{\mathrm{x}}\right)$ was expressed as the number of offspring per week per reproducing female and hermaphrodite (modified after Levin et al. 1987).

For demographic analysis, $\lambda$ was calculated directly from age-specific data on longevity and fecundity in the different FLU treatments using a simplified 2-stage model (Calow et al. 1997):

$$
1=\mathrm{n} S_{\mathrm{j}} \lambda^{-t_{\mathrm{j}}}+S_{\mathrm{a}} \lambda^{-t_{\mathrm{a}}}
$$

where $n=$ average number of offspring per brood per reproductive individual, $S_{\mathrm{j}}=$ juvenile survival (proportion surviving from birth to first reproduction), $t_{\mathrm{j}}=$ mean age at first reproduction, $S_{\text {a }}$ adult survival (average proportion of adult females/hermaphrodites surviving between broods estimated over reproductive period) and $t_{\mathrm{a}}=$ average time between broods. All time units used to calculate $\lambda$ are in weeks. The reproductive period is defined as the time between first and last breeding attempt averaged for each treatment. In cases of 1 brood per female, the second term to the right of the plus sign drops out of Eq. (3).

For SSPR, the fixed sediment samples were sieved through a $130 \mu \mathrm{m}$ mesh to retrieve the fecal pellets (= sediment processed), and tubes and mucus without attached pellets were removed with forceps. The pellet samples were dried at $105^{\circ} \mathrm{C}(24 \mathrm{~h})$ and subsequently weighed. Worm wet wt was converted to dry wt by multiplying by 0.13 (Méndez et al. unpubl. data). We estimated SSPR (feeding rate) as:

$$
\begin{aligned}
\text { SSPR }= & (\text { dry wt of pellets }) / \\
& (\text { mean worm dry wt } \times \text { time in days })
\end{aligned}
$$

This gives a measure of feeding rate per unit worm body-size per day.

Statistics. Effects of FLU exposure on age and size at maturity, age at first reproduction, brood size, time between broods, and SSPR were analyzed separately for each species using 1-way ANOVA. Multiple comparisons were performed using Tukey's HSD test. In most cases the data deviated somewhat from normality and were not improved by transformation. Therefore ANOVA results were confirmed by Kruskal-Wallis analyses and by examination of notched box plots (McGill et al. 1978). These analyses were performed using SYSTAT Version 8.02. Effects of FLU exposure on survival were analyzed using Statistica Version 5, Survival Analysis Module, which is designed to handle censored data. To compare survival times among treatment groups, a score was first assigned to each survival time using Mantel's procedure; next a chi-square value was computed based on the sums (for each group) of this score. A significance level of 0.05 was employed throughout.

Parameters for which we obtained single values per treatment (i.e., survival times, percent total females, \% reproducing females and/or hermaphrodites, fecundity, and $\lambda$ ) were compared qualitatively.

\section{RESULTS}

\section{Fluoranthene}

The measured FLU concentrations in the experimental sediments were generally close to nominal concentrations (Table 1). They differed considerably only from nominal 40 and $80 \mu \mathrm{g} \mathrm{g}^{-1}$ FLU, and these will be referred to as 50 and $95 \mu \mathrm{g} \mathrm{g}^{-1}$ FLU treatments, respectively.

\section{Survival}

No significant differences in the age-specific survival curves of the 3 Capitella species among the controls and lower FLU exposures (up to $50 \mu \mathrm{g} \mathrm{g}^{-1} \mathrm{FLU}$ : Fig. 1) could be detected. At $95 \mu \mathrm{g} \mathrm{g}^{-1}$ FLU; median survival time $\left(\mathrm{LT}_{50}\right)$ was lowest in Capitella sp. $\mathrm{S}$,

Table 1. Nominal and average $( \pm 1 \mathrm{SD})$ measured fluoranthene concentrations $\left(\mathrm{FLU}_{i} \mu \mathrm{g} \mathrm{g}^{-1}\right)$ in the experimental sedient ( $n=4$ repeated measurements)

\begin{tabular}{|cc|}
\hline Nominal FLU & Measured FLU \\
\hline 0 & $1.79 \pm 1.07$ \\
5 & $6.61 \pm 1.46$ \\
10 & $10.24 \pm 0.77$ \\
20 & $21.50 \pm 1.64$ \\
40 & $51.83 \pm 4.60$ \\
80 & $94.79 \pm 25.09$ \\
\hline
\end{tabular}


whereas Capitella sp. M showed a considerably higher $\mathrm{LT}_{50}$, and Capitella sp. I was most tolerant to FLU (Table 2).

Chronic FLU exposure significantly reduced survival time in Capitella sp. $\mathrm{S}\left(\chi^{2}=11.986, \mathrm{df}=5, \mathrm{p}=0.035\right)$, but not in Capitella sp. $\mathrm{M}\left(\chi^{2}=7.112, \mathrm{df}=5, \mathrm{p}=0.213\right)$ or Capitella sp. I $\left(\chi^{2}=7.097, \mathrm{df}=5, \mathrm{p}=0.214\right)$.

\section{Growth}

At the start of the experiments (Day 0), the average body volume of 10 randomly chosen juveniles was $0.007 \pm 0.003 \mathrm{~mm}^{3}$ in Capitella sp. S (3 to $4 \mathrm{~d}$ old), $0.015 \pm 0.024 \mathrm{~mm}^{3}$ in Capitella sp. M (5 to $6 \mathrm{~d}$ old), and $0.009 \pm 0.002 \mathrm{~mm}^{3}$ in Capitella sp. I (5 to $6 \mathrm{~d}$ old).
Body volumes over time differed significantly among species (Fig. 2). In all treatments $(n=6)$ Capitella sp. S grew more slowly and became mature at the smallest size, whereas Capitella sp. $\mathrm{M}$ and Capitella sp. I matured at larger body volumes. FLU had no detectable effect on body volume at maturity in Capitella sp. S (ANOVA: df $=5,23 ; F=1.374 ; \mathrm{p}=0.270$ ) or in Capitella sp. M (ANOVA: df $=5,24 ; F=2.021$; $\mathrm{p}=0.112$ ), but significantly reduced body volume at maturity in Capitella sp. I (ANOVA: df $=5,24 ; F=$ $3.762 ; \mathrm{p}=0.012$ ), with worms exposed to 50 and $95 \mu \mathrm{g} \mathrm{g}^{-1}$ FLU having smaller body volumes than control-group worms.

Juvenile SGR until maturity was lowest in Capitella sp. S, whereas Capitella sp. I showed highest growth rates (Fig. 3). FLU exposure significantly reduced juve-
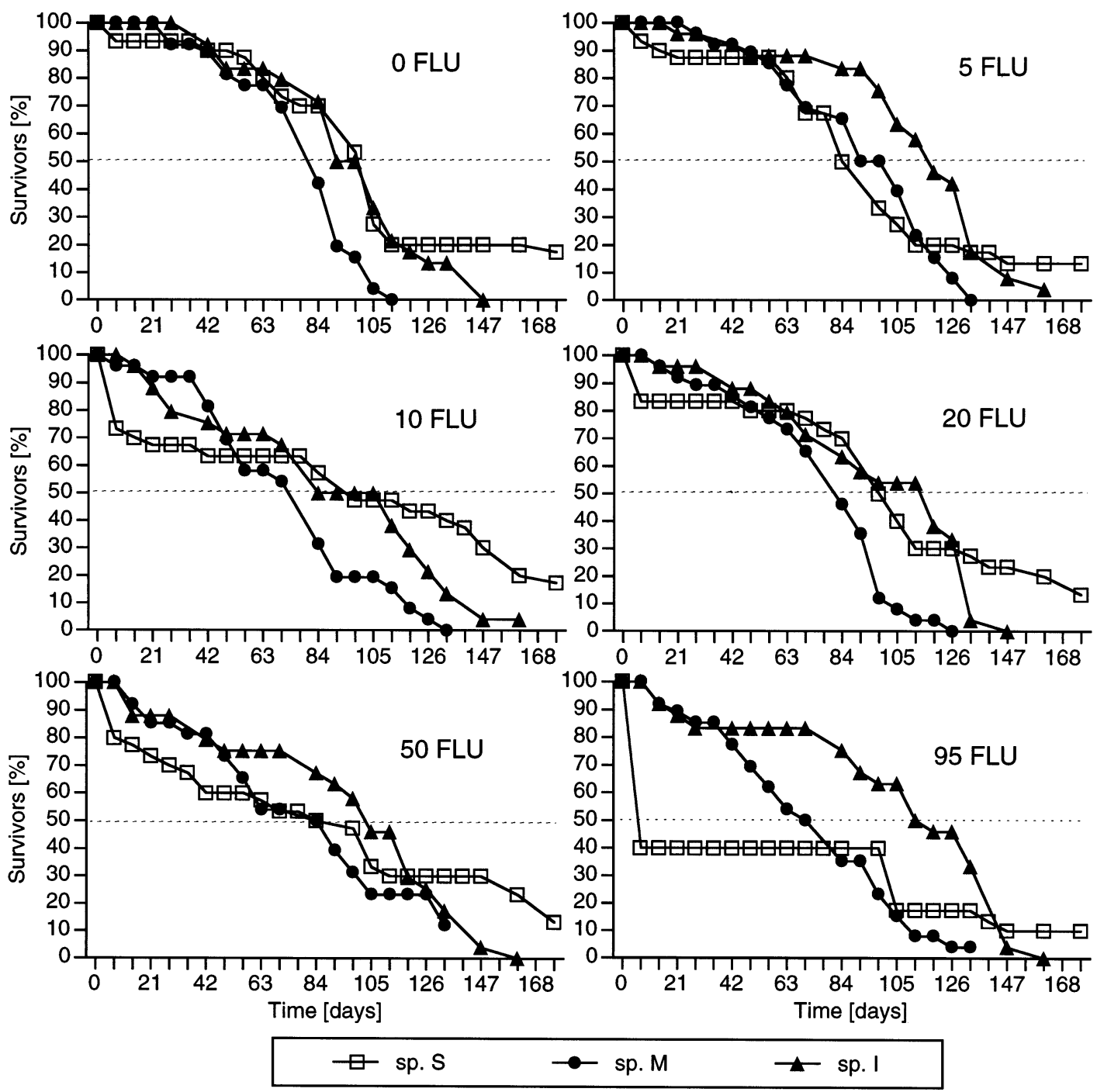

Fig. 1. Capitella sp. S, Capitella sp. M, and Capitella sp. I. Age-specific survivorship in different fluoranthene (FLU) treatments. Dashed lines = graphic median survival times $\left(\mathrm{LT}_{50}\right)$ 
Table 2. Capitella sp. S, Capitella sp. M, and Capitella sp. I. Median survival times $\left(\mathrm{LT}_{50}\right)$ and average $( \pm 1 \mathrm{SD})$ vital rates in different FLU treatments $\left(S_{\mathrm{j}}\right.$ : juvenile survival, $S_{\mathrm{a}}$ : adult survival, age at maturity (n $=6$ to 24 worms), $t_{\mathrm{j}}$ : age at first reproduction ( $\mathrm{n}=2$ to 15 worms), $t_{\mathrm{a}}$ : time between broods ( $\mathrm{n}=2$ to 16 broods), 1: 1 brood, $\mathrm{x}$ : no reproduction). See 'Materials and methods' for further details

\begin{tabular}{|c|c|c|c|c|c|c|}
\hline \multirow{2}{*}{ Parameter } & \multicolumn{6}{|c|}{ FLU $\left(\mu g g^{-1}\right)$} \\
\hline & 0 & 5 & 10 & 20 & 50 & 95 \\
\hline \multicolumn{7}{|l|}{ Capitella sp. S } \\
\hline $\mathrm{LT}_{50}(\mathrm{~d})$ & 108 & 101 & 101 & 104 & 94 & 10 \\
\hline$S_{\mathrm{j}}$ (proportion) & 0.20 & 0.20 & 0.47 & 0.30 & 0.30 & $\times$ \\
\hline$S_{\mathrm{a}}$ (proportion) & 0 & 0 & 0 & 0 & 0 & $x$ \\
\hline Age at maturity (d) & $59 \pm 1$ & $63 \pm 7$ & $61 \pm 5$ & $62 \pm 5$ & $62 \pm 5$ & $67 \pm 7$ \\
\hline$t_{\mathrm{j}}(\mathrm{d})$ & $115 \pm 20$ & 129 & $110 \pm 17$ & $115 \pm 20$ & $115 \pm 21$ & $\times$ \\
\hline$t_{\mathrm{a}}(\mathrm{d})$ & 1 & 1 & 1 & 1 & 1 & 1 \\
\hline \multicolumn{7}{|l|}{ Capitella sp. $\mathrm{M}$} \\
\hline $\mathrm{LT}_{50}(\mathrm{~d})$ & 90 & 105 & 90 & 90 & 94 & 83 \\
\hline$S_{\mathrm{j}}$ (proportion) & 0.77 & 0.77 & 0.54 & 0.65 & 0.54 & 0.35 \\
\hline$S_{\mathrm{a}}$ (proportion) & 0.61 & 0.76 & 0.75 & 0.75 & 0.75 & 0 \\
\hline Age at maturity (d) & $53 \pm 11$ & $55 \pm 3$ & $55 \pm 3$ & $51 \pm 8$ & $52 \pm 9$ & $59 \pm 8$ \\
\hline$t_{\mathrm{j}}(\mathrm{d})$ & $58 \pm 5$ & $70 \pm 23$ & $80 \pm 34$ & $74 \pm 14$ & $67 \pm 10$ & $84 \pm 21$ \\
\hline$t_{\mathrm{a}}(\mathrm{d})$ & $11 \pm 4$ & $8 \pm 3$ & 12 & 8 & $16 \pm 11$ & 1 \\
\hline \multicolumn{7}{|l|}{ Capitella sp. I } \\
\hline $\mathrm{LT}_{50}(\mathrm{~d})$ & 104 & 124 & 103 & 124 & 110 & 131 \\
\hline$S_{\mathrm{j}}$ (proportion) & 0.79 & 0.83 & 0.50 & 0.58 & 0.67 & 0.67 \\
\hline$S_{\mathrm{a}}$ (proportion) & 0.79 & 0.72 & 0.68 & 0.70 & 0.63 & 0.74 \\
\hline Age at maturity (d) & $41 \pm 10$ & $44 \pm 11$ & $56 \pm 13$ & $54 \pm 10$ & $58 \pm 12$ & $62 \pm 13$ \\
\hline$t_{\mathrm{j}}(\mathrm{d})$ & $76 \pm 10$ & $85 \pm 12$ & $88 \pm 11$ & $97 \pm 13$ & $88 \pm 14$ & $96 \pm 14$ \\
\hline$t_{\mathrm{a}}(\mathrm{d})$ & $19 \pm 9$ & $13 \pm 5$ & $13 \pm 6$ & $11 \pm 4$ & $10 \pm 4$ & $7 \pm 10$ \\
\hline
\end{tabular}

nile SGR in Capitella sp. S (ANOVA: df $=5,23 ; F=$ 7.666; $\mathrm{p}=0.0002$ ) and Capitella sp. I (ANOVA: $\mathrm{df}=5$, 24; $F=22.208 ; \mathrm{p}<0.0001$ ), with worms exposed to $95 \mathrm{\mu g} \mathrm{g}^{-1}$ FLU having significantly lower growth rates than worms in all other treatment groups. In Capitella sp. $\mathrm{M}$ toxic exposure did not significantly reduce the control SGR (ANOVA: $\mathrm{df}=5,24 ; F=1.463 ; \mathrm{p}=0.239$ ).

\section{Reproductive parameters}

In all treatments, Capitella sp. S matured either into females (F) (Table 3) or males. In Capitella spp. $\mathrm{M}$ and $\mathrm{I}$, also hermaphrodites $(\mathrm{H})$ were found in the controls as well as in the toxic exposures (except for no $\mathrm{H}$ in Capitella sp. $\mathrm{M}$ at $95 \mathrm{\mu g} \mathrm{g}^{-1}$ FLU). It is interesting to note that in Capitella sp. I all $\mathrm{H}$ showed genital spines first (protandrous), whereas in $\mathrm{H}$ of Capitella sp. $\mathrm{M}$ female features appeared first (proterogynous), before developing into simultaneous $\mathrm{H}$.

The average age at maturity $(\mathrm{n}=6)$ was highest in Capitella sp. S, whereas Capitella sp. M and Capitella sp. I matured earlier (Table 2). Exposure to FLU significantly increased age at maturity in Capitella sp. S (ANOVA: $\mathrm{df}=5,95 ; F=3.173 ; \mathrm{p}=0.011 ; 95 \mu \mathrm{g} \mathrm{g}{ }^{-1} \mathrm{FLU}$ significantly longer than control) and in Capitella sp. I (ANOVA: $\mathrm{df}=5,100 ; F=13.104 ; \mathrm{p}<0.001 ; 50$ and $95 \mathrm{\mu g} \mathrm{g}^{-1}$ FLU significantly longer than control and
$5 \mu \mathrm{g} \mathrm{g}^{-1}$ FLU significantly shorter than all higher concentrations). FLU had no detectable effect on age at maturity in Capitella sp. M (ANOVA: df $=5,39 ; F=$ 0.605; $\mathrm{p}=0.696$ ).

In Capitella sp. S a low percentage of $\mathrm{F}$ reproduced successfully (Table 3), whereas in Capitella sp. M a higher percentage of $\mathrm{F} / \mathrm{H}$ reproduced and in Capitella sp. I almost all F/H reproduced successfully. Highest FLU exposures completely inhibited reproduction in Capitella sp. S, whereas no significant FLU effect on the fraction of individuals that reproduced was observed in the 2 other species.

In all treatments, Capitella sp. S started to reproduce latest, whereas first reproduction occurred markedly earlier in Capitella spp. M and I (Table 2). For those worms that reproduced, exposure to FLU had no detectable effect on age at first reproduction in Capitella sp. S (ANOVA for 0 to $50 \mu \mathrm{g} \mathrm{g}^{-1}$ FLU: $\mathrm{df}=4$, $14 ; F=0.236 ; \mathrm{p}=0.914$ ). Exposure to FLU had no detectable effect on age at first reproduction in Capitella sp. $\mathrm{M}$ (ANOVA: $\mathrm{df}=5,17 ; F=1.221 ; \mathrm{p}=$ 0.342 ), but significantly increased age at first reproduction in Capitella sp. I (ANOVA: $\mathrm{df}=5,37 ; F=2.767$; $\mathrm{p}=0.032$ ).

Capitella sp. S reproduced only once per female, whereas Capitella spp. M and I females and hermaphrodites made several breeding attempts during their adult period (Table 3). Time between broods in these 2 

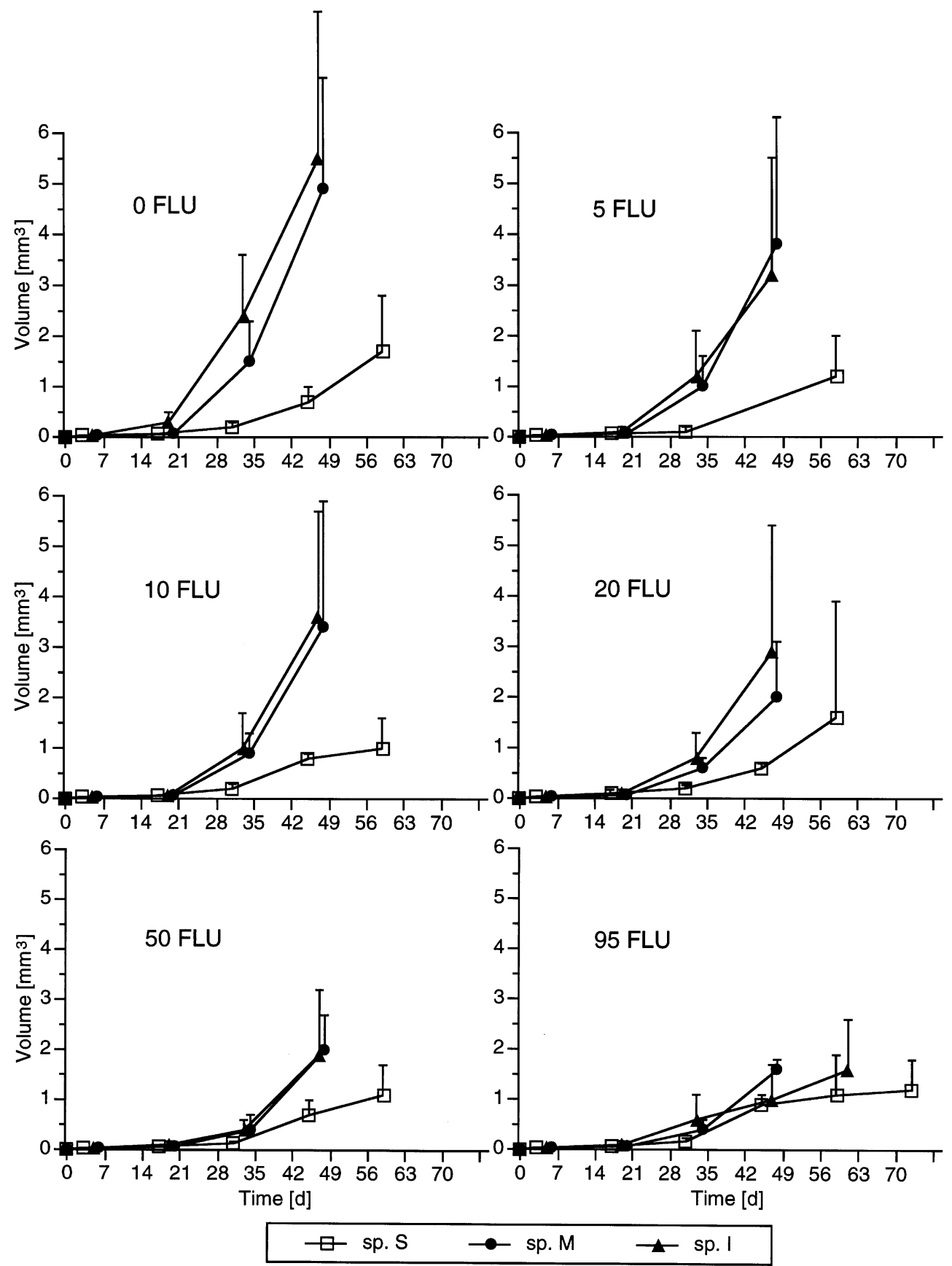

Fig. 2. Capitella sp. S, Capitella sp. M, and Capitella sp. I. Average $\left(+1 \mathrm{SD}, \mathrm{n}=5\right.$ worms) body volume $\left(\mathrm{mm}^{3}\right)$ over time in different FLU treatments

species was similar (Table 2). Capitella sp. I was the only species for which enough data were available for statistical analysis (in Capitella sp. M only 1 individual had $>1$ brood in the 10 and $20 \mu \mathrm{g} \mathrm{g}^{-1}$ FLU exposure groups, and no individuals reproduced more than once at $\left.95 \mu \mathrm{g} \mathrm{g}^{-1} \mathrm{FLU}\right)$. Effects of FLU on time between broods in Capitella sp. I were not significant (ANOVA: $\mathrm{df}=5,52 ; F=2.174 ; \mathrm{p}=0.071$ ).
Comparisons of age-specific fecundity in the controls indicate that Capitella sp. S with benthic juveniles had the lowest reproductive output, with a low lifetime fecundity per reproducing female and the shortest reproductive period (Fig. 4). In contrast, the lecithotroph Capitella spp. $\mathrm{M}$ and I showed substantially higher fecundities and longer reproductive periods. 
Table 3. Capitella sp. S, Capitella sp. M, and Capitella sp. I. Fraction of females (F) and hermaphrodites (H), and reproductive parameters in different FLU treatments (n: number of offspring per brood per reproductive individual, $\times$ : no reproduction)

\begin{tabular}{|c|c|c|c|c|c|c|}
\hline \multirow{2}{*}{ Parameter } & \multicolumn{6}{|c|}{ FLU $\left(\mu g g^{-1}\right)$} \\
\hline & 0 & 5 & 10 & 20 & 50 & 95 \\
\hline \multicolumn{7}{|l|}{ Capitella sp. S } \\
\hline Total F (\%) & 69 & 63 & 84 & 74 & 69 & 75 \\
\hline Reproducing F (\%) & 17 & 7 & 19 & 6 & 18 & $x$ \\
\hline Broods/reproducing F & 1 & 1 & 1 & 1 & 1 & $x$ \\
\hline Total offspring & 41 & 18 & 41 & 13 & 55 & $\times$ \\
\hline $\mathrm{n}$ & 10.3 & 18 & 4.6 & 13 & 13.8 & $\times$ \\
\hline \multicolumn{7}{|l|}{ Capitella sp. $\mathrm{M}$} \\
\hline Total F (\%) & 25 & 10 & 14 & 12 & 12 & 19 \\
\hline Total H (\%) & 20 & 20 & 21 & 12 & 6 & 0 \\
\hline Reproducing F/H (\%) & 67 & 83 & 20 & 50 & 67 & 33 \\
\hline Broods/reproducing F/H & 1.5 & 2.0 & 2.0 & 1.5 & 2.0 & 1.0 \\
\hline Total offspring & 843 & 657 & 119 & 210 & 85 & 52 \\
\hline $\mathrm{n}$ & 15.6 & 13.1 & 59.5 & 35 & 10.6 & 52 \\
\hline \multicolumn{7}{|l|}{ Capitella sp. I } \\
\hline Total F (\%) & 5 & 6 & 8 & 8 & 7 & 6 \\
\hline Total H (\%) & 42 & 39 & 42 & 39 & 53 & 50 \\
\hline Reproducing F/H (\%) & 78 & 100 & 100 & 100 & 100 & 78 \\
\hline Broods/reproducing F/H & 2.1 & 2.7 & 2.0 & 2.2 & 2.0 & 2.3 \\
\hline Total offspring & 1408 & 1842 & 541 & 516 & 1181 & 524 \\
\hline $\mathrm{n}$ & 13.4 & 8.5 & 7.5 & 6.6 & 12.1 & 4.7 \\
\hline
\end{tabular}

In all treatments, Capitella sp. S had smallest brood sizes, whereas Capitella spp. M and I reproduced with substantially higher numbers of larvae per brood (Fig. 5). So few individuals of Capitella sp. S reproduced that statistical analysis of FLU effects could not be performed. Exposure to FLU had no effect on brood size in Capitella sp. M (ANOVA: df $=5,25 ; F=0.784$; $\mathrm{p}=0.571$ ), but significantly reduced number of larvae per brood in Capitella sp. I (ANOVA: df $=5,86 ; F=$
3.705; $\mathrm{p}=0.004 ;$ control higher than 20 and $95 \mu \mathrm{g} \mathrm{g}^{-1}$ FLU).

Under control conditions, Capitella sp. S showed the lowest $\lambda$, having values just above 1 , whereas Capitella spp. $M$ and I had higher $\lambda$ values, indicating increasing population sizes (Fig. 6). At the highest FLU exposure, $\lambda$ of Capitella sp. S dropped to zero (indicating population extinction), whereas $\lambda$ of Capitella spp. $M$ and I were reduced by $\sim 11 \%$ but remained above 1 .

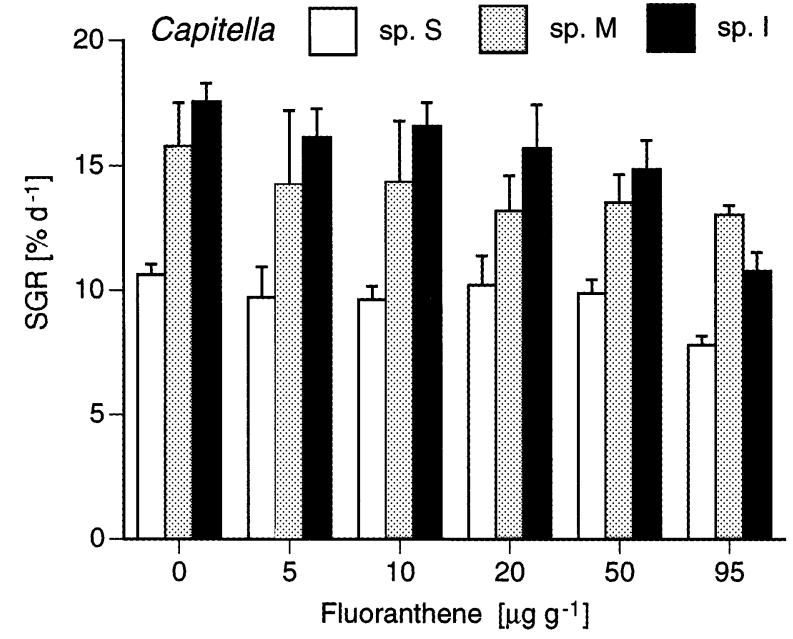

Fig. 3. Capitella sp. S, Capitella sp. M, and Capitella sp. I. average (+1 $\mathrm{SD}, \mathrm{n}=5$ worms) juvenile-specific growth rate (SGR) until maturity in different FLU treatments

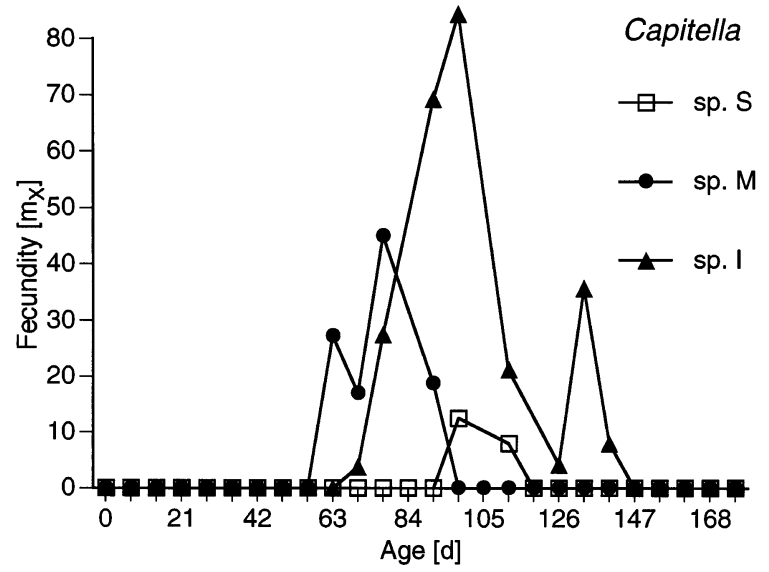

Fig. 4. Capitella sp. S, Capitella sp. M, and Capitella sp. I. Age-specific weekly offspring per reproducing female and hermaphrodite (= fecundity, $m_{\mathrm{x}}$ ) in control treatments 


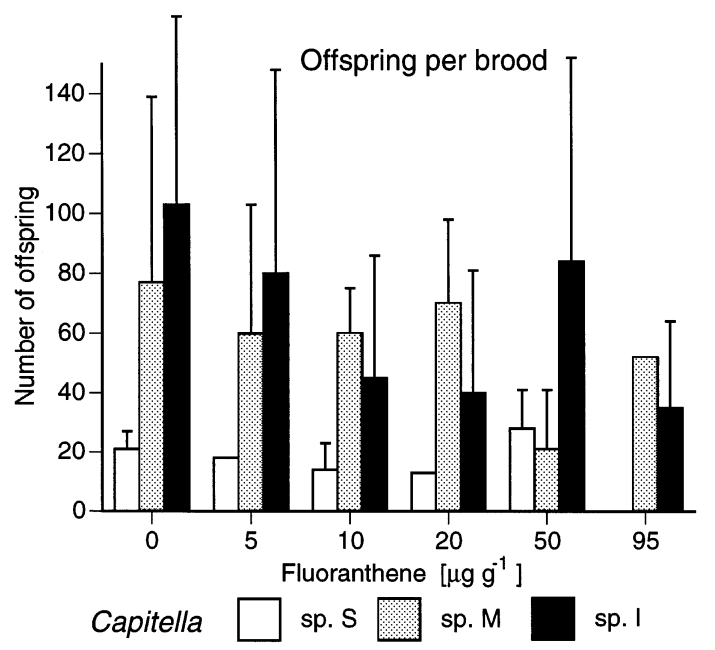

Fig. 5. Capitella sp. S, Capitella sp. M, and Capitella sp. I. Average (+1 SD, $\mathrm{n}=2$ to 23 broods) number of offspring per brood (= brood size) in different FLU treatments

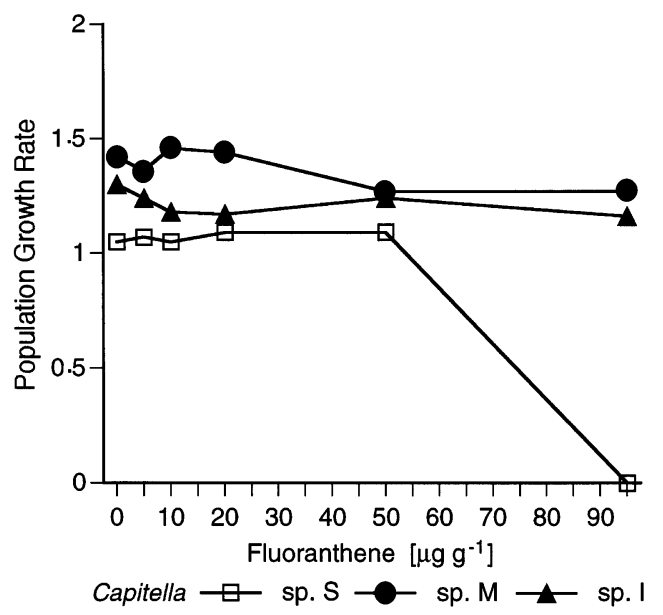

Fig. 6. Capitella sp. S, Capitella sp. M, and Capitella sp. I. Population growth rates $(\lambda)$ in different FLU treatments

\section{Feeding rates}

There were marked differences in SSPR among the Capitella species (Fig. 7). In all treatments, Capitella sp. S showed lower feeding rates than Capitella spp. M and I. There were no detectable effects of FLU on SSPR in Capitella sp. S (ANOVA: $\mathrm{df}=5,31 ; F=1.035 ; \mathrm{p}=$ 0.414). For Capitella sp. M (ANOVA [no data for $50 \mu \mathrm{g}$ $\mathrm{g}^{-1}$ FLU]: $\mathrm{df}=4,14 ; F=3.231 ; \mathrm{p}=0.045$; control rates $>10 \mathrm{\mu g} \mathrm{g}^{-1} \mathrm{FLU}$ ) and Capitella sp. I (ANOVA: $\mathrm{df}=5,39$; $F=5.091 ; \mathrm{p}=0.001 ; 5 \mu \mathrm{g} \mathrm{g}^{-1}$ FLU feeding rates $>10 \mu \mathrm{g}$ $\mathrm{g}^{-1}$ FLU, and 10 and $20 \mu \mathrm{g} \mathrm{g}^{-1}$ FLU feeding rates $<95 \mu \mathrm{g} \mathrm{g}^{-1}$ FLU), FLU had a significant effect on SSPR but the effects were not monotonic with respect to increasing FLU exposure (Fig. 7).

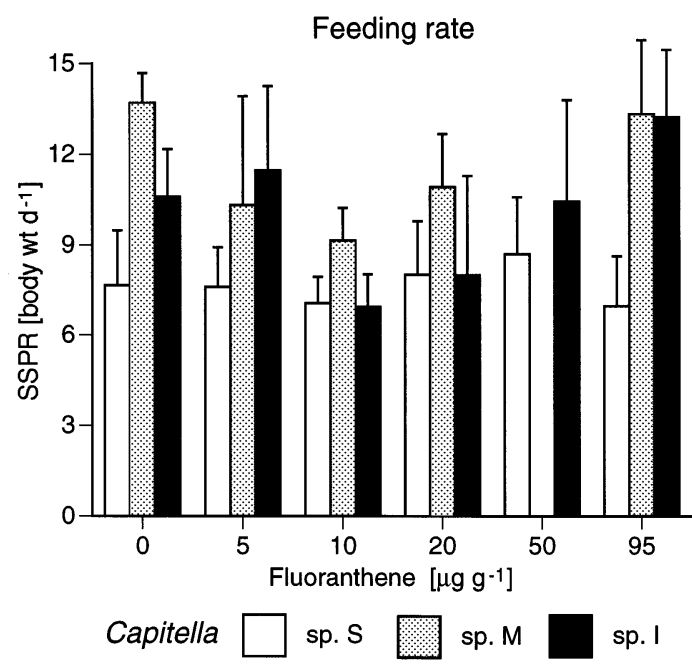

Fig. 7. Capitella sp. S, Capitella sp. M, and Capitella sp. I. Average ( $+1 \mathrm{SD}, \mathrm{n}=3$ to 17 worms) size-specific sedimentprocessing rate $(\mathrm{SSPR}=$ feeding rate) in different FLU treatments

\section{DISCUSSION}

\section{Interspecific differences}

This study has shown that the 3 Capitella species differ markedly in a number of life-history traits and hence in their $\lambda$ under identical non-toxic and densityindependent laboratory conditions (see also summary in Table 4). Capitella sp. S with direct larval development grew slowest, matured at the smallest body volume, and reproduced latest with lowest fecundity, thus having the lowest $\lambda$. The lecithotrophic Capitella sp. M matured at an intermediate body volume, reproduced earliest with an intermediate fecundity, and had the highest $\lambda$ under control conditions. Capitella sp. I, also with lecithotrophic free-swimming larvae, showed highest juvenile SGR, and matured at the largest body volume. This species had an intermediate reproductive age, the highest fecundity, longest reproductive period, and intermediate $\lambda$ under control conditions. Despite the occurrence of hermaphrodites in Capitella spp. $M$ and I, the proportion of potential egg-laying individuals was not higher in these 2 species than in Capitella sp. S. However, the percentage of $\mathrm{F} / \mathrm{H}$ that actually laid eggs was substantially lower in Capitella sp. S than in the other 2 species (Table 3).

The marked differences in life-history variables, as shown in detail in this study, are of particular interest for this taxonomically difficult species group. They confirm interspecific differences within the complex in reproductive biology as first shown by Grassle \& Grassle (1976) and recently by Méndez et al. (unpubl. data) that should be included in further species 
Table 4. Capitella spp. Summary of differences in developmental modes and life-history parameters under control conditions and FLU effects. F: female; M: male; H: hermaphrodite; SGR: juvenile specific growth rate; -: reduced; +: increased; ne: no effect

\begin{tabular}{|lccc|}
\hline & Capitella sp. S & Capitella sp. M & Capitella sp. I \\
\hline Larval mode & Direct & Lecithotroph & Lecithotroph \\
Reproductive mode & F, M & F, M, H & F, M, H \\
Maturation size $\left(\mathrm{mm}^{3}\right)$ & $2.0 \pm 0.4$ & $5.0 \pm 2.2$ & $6.2 \pm 1.7$ \\
SGR $\left(\% \mathrm{~d}^{-1}\right)$ & $9.7 \pm 1.0$ & $14.0 \pm 1.0$ & $15.3 \pm 2.4$ \\
Reproduction age $(\mathrm{d})$ & $115 \pm 20$ & $58 \pm 5$ & $76 \pm 10$ \\
Lifetime fecundity & 22 & 97 & 221 \\
$\quad$ (offspring per reproduc- & & & \\
tive individual) & & & $103 \pm 63$ \\
Offspring per brood & $22 \pm 6$ & $77 \pm 62$ & 1.30 \\
Population growth rate & 1.05 & 1.42 & \\
& & & ne \\
FLU effects & - & ne & - \\
LT & ne & ne & - \\
Maturation size & - & ne & + \\
SGR & + & ne & ne \\
Maturation age & ne & ne & - \\
Reproduction age & ne & ne & \\
Inhibition of reproduction & & & \\
Brood size & & &
\end{tabular}

descriptions. In the Capitella complex a third developmental mode exists, with extremely high numbers of planktotrophic trochophore larvae leaving the maternal tube (Grassle \& Grassle 1976, Méndez et al. unpubl. data), which are believed to have greatest dispersal capabilities. Attempts to get such larvae to metamorphose in the laboratory failed, and thus lifetable data are not available. However, these species have an enormous fecundity with brood sizes of $>3500$ larvae, and the potential for a long-dispersal larval stage (up to several weeks). Following the early study of Grassle \& Grassle (1974), in which different benthic polychaete species were ranked in terms of their degree of opportunism defined by early maturation, their ability to increase rapidly to large population sizes, and their dispersal capabilities, we suggest a similar ranking in order of decreasing degree of opportunism within the Capitella complex according to lifehistory type. We suggest that the majority of described Capitella species for which reproductive data exist can be assigned to 1 of 3 groups: (1) Most opportunistic Capitella spp. Ia, III (Grassle \& Grassle 1976), Capitella capitata Type 2 (Pearson \& Pearson 1991), Capitella sp. L (Gamenick \& Giere 1994), Capitella Types K and Ct (Méndez et al. unpubl. data), with large brood sizes of small eggs and trochophore larvae that have a long dispersal time in the plankton; (2) Capitella spp. I, II (Grassle \& Grassle 1976, this study), Capitella sp. M (Gamenick et al. 1998a, and this study) with lecithotrophic metatrochophore larve, with a shorter dispersal stage (up to several days); (3) less opportunistic-Capitella spp. IIIa, II (Grassle \& Grassle 1976), and Capitella sp. S (Méndez et al. unpubl. data, and this study), with direct benthic development and small brood sizes.

In the present study, the combination of differences in vital rates among species led to different population growth rates under identical non-toxic conditions. Capitella sp. S showed the lowest $\lambda$ of (1.05), suggesting that this species has a low recolonization potential. From an ecological perspective this means that as a consequence of its demographic characteristics $\mathrm{Ca}$ pitella sp. S, and presumably the other species of this complex with a benthic developmental mode, may not belong to the 'typical' early colonizers following habitat disturbances.

In contrast, both lecithotrophic species Capitella spp. $\mathrm{M}(\lambda$ of 1.42$)$ and I ( $\lambda$ of 1.30 ) have higher $\lambda$ under identical conditions, which can be basically explained through earlier reproduction (Capitella sp. $\mathrm{M})$, and higher fecundity (Capitella sp. I), as indicated previously for Capitella sp. I (Bridges et al. 1994, Levin et al. 1996). The lecithotrophic larvae of Capitella sp. I are able to delay metamorphosis and can select suitable settlement habitats, thus enhancing their survival capabilities (Grassle \& Butman 1989, Pechenik \& Cerulli 1991). All these life-history characters favour the ability of Capitella sp. I, and presumably Capitella sp. M, to achieve high population densities within short time periods, enabling them to colonize and persist in extreme habitats, such as unpredictable hydrothermal vent areas and eutrophic sewage outfalls.

\section{Toxic effects}

Chronic exposure to inreasing FLU concentrations revealed species differences in individual- and population-level toxic responses (Table 4). The highest FLU concentrations of $95 \mu \mathrm{g} \mathrm{g}^{-1}$ reduced juvenile survival markedly, and completely inhibited reproduction only in Capitella sp. S. The toxicant reduced juvenile SGR and delayed maturation in Capitella spp. S and I, and delayed reproduction as well as adult body size and brood size in Capitella sp. I, whereas individual lifehistory traits of Capitella sp. $M$ were not affected. In terms of $\lambda$, this means that highest FLU exposures would be likely to lead to population extinction in 
Capitella sp. S, while population dynamics of Capitella spp. I and $M$ would suffer less impairment. We expect these patterns to be more complicated under densitydependent field conditions (i.e., food limitation), which might mask toxic effects on population dynamics at low FLU concentrations and magnify them at high levels (Linke-Gamenick et al. 1999).

However, the demographic results of this study basically mirror data on individual physiological performance (i.e., survival, respiration rates, anaerobiosis) under FLU exposure, and indicate a high sensitivity of Capitella sp. S relative to Capitella spp. M and I (Linke-Gamenick et al. 2000). At FLU concentrations of $100 \mathrm{\mu g} \mathrm{g}^{-1}$, Capitella sp. S showed enhanced total metabolism associated with decreased survival. LinkeGamenick et al. postulated that increased metabolic costs combined with apparently negligible food intake, as observed in Capitella sp. S, could explain the high mortality rates. In this study, slightly lower FLU levels were used, and adult survival and feeding rates of Capitella sp. S (and of the other 2 species) were not affected, as shown also by Méndez et al. (unpubl. data) under similar conditions. However, these sublethal concentrations nevertheless inhibited reproduction completely, leading to population extinction. Thus, toxicity tests of mortality alone would have severely underestimated population-level consequences of toxic exposure.

Some life-history traits of Capitella sp. I were affected by FLU exposure, whereas reproductive parameters in Capitella sp. M showed no toxic response. In Capitella sp. I, reproduction was delayed and brood size impaired, parameters that are important contributors to $\lambda$ in this species (Levin et al. 1996, Hansen et al. 1999). However, in both species an $11 \%$ decline in $\lambda$ with increasing toxic exposure was observed. We believe the reason why for Capitella sp. M we detected no significant effects on individual vital rates but a decline in $\lambda$, is the result of reduced sample size with increasing toxic concentration, resulting in very low statistical power for some of the vital rate comparisons.

In ecotoxicological terms, this case study on different Capitella species confirms that toxic responses of single individual-level traits cannot directly be translated to population-level responses as shown by several authors using decomposition and sensitivity analyses (Caswell 1989, Kammenga et al. 1996, Levin et al. 1996, Hansen et al. 1999), and recently reviewed by Forbes \& Calow (1999). We would like to postulate this also for the linkage of individual feeding rates to $\lambda$. In this study, no clear toxic effects on individual feeding rates were detected, even at FLU exposures that led to population extinction in one of the species (i.e., Capitella sp. S). This is of particular interest in the use of energy budget models as a tool for linking individ-

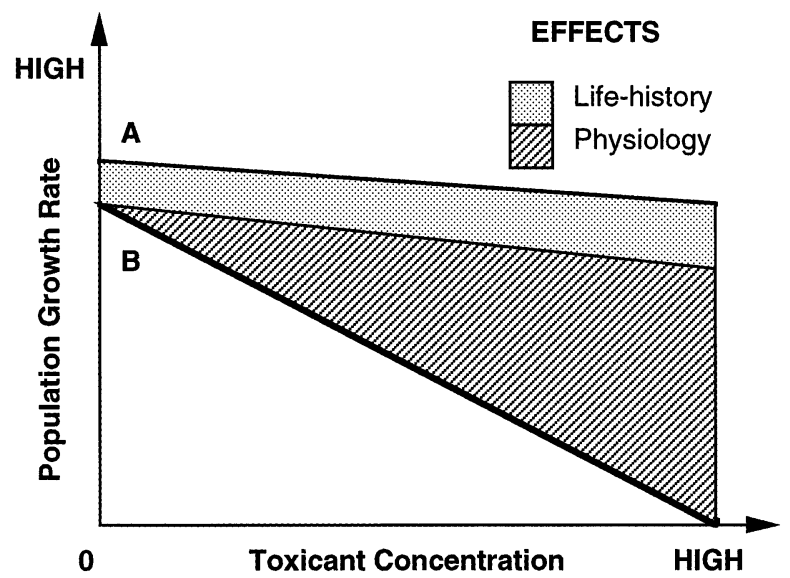

Fig. 8. Schematic approach to partition effects of life-history strategy and physiological sensitivity on $\lambda$ differences in Species A and B in relation to toxicant exposure. (Species A represents Capitella spp. M or I, Species B Capitella sp. S)

ual-level effects on e.g., energy intake, to populationlevel consequences (Kooijman 1985). If based on the general assumption that toxic exposure results at first in a decrease in food intake, such models could underestimate population-level effects.

If we assume that all the differences in $\lambda$ among species under control conditions are entirely due to different life-history strategies, and that changes in $\lambda$ (within species) with increasing toxic exposure are due to physiological sensitivities of one or more vital rates, then changes in the magnitude of $\lambda$ differences among species as toxic concentration increases can be attributed to differences in physiological sensitivity among species. This is shown conceptually in Fig. 8, where species A represents Capitella spp. M or I, while species B represents Capitella sp. S. We assume in the present study that there are no major differences among species in which vital rates are affected by toxic exposure and that these have different elasticities with respect to $\lambda$. This schematic approach allows us to partition the effects of life-history and physiology effects on $\lambda$ differences among species in relation to toxic exposure. With respect to Capitella spp. I and S, the higher physiological sensitivity of Capitella sp. S exacerbates life-history differences under toxic exposure. A total of $67 \%$ of the $\lambda$ differences found between Capitella spp. I and $\mathrm{S}$ at the highest toxic exposure could be attributed to physiology, whereas $33 \%$ could be attributed to life-history (Fig. 8).

\section{Conclusions}

In Capitella spp. M and I, the combination of opportunistic life-history features, reproductive flexibility, 
and physiological adaptations enables them to colonize habitats rapidly after local disturbance and to persist in stressed and unpredictable environments, whereas in Capitella sp. S population extinction under FLU stress results mainly from the physiological sensitivity of this species.

Examining changes in $\lambda$ differences among Capitella species with increasing toxic exposure may provide insight into the relative importance of life-history and physiology in explaining differences in population dynamics.

In addition, we would like to stress that some species of this complex, e.g., Capitella sp. S, cannot be regarded as a 'typical' opportunistic species, because of their physiological sensitivity in combination with their demographic characteristics (i.e., low population growth-potential).

Acknowledgements. This study was supported by a grant from the Danish Natural Science Research Council, No. 9700248 to V.E.F. We are grateful to Lise Maarup for her substantial help with FLU extraction and HPLC analysis, and to R. M. Sibly, P. Calow and F. T. Hansen for stimulating discussions and helpful suggestions. We wish to thank 3 anonymous referees for their constructive comments.

\section{LITERATURE CITED}

Bridges TS, Levin LA, Cabrera D, Plaia G (1994) Effects of sediment amended with sewage, algae, or hydrocarbons on growth and reproduction in two opportunistic polychaetes. J Exp Mar Biol Ecol 177:99-119

Calow P, Sibly RM, Forbes VE (1997) Risk assessment on the basis of simplified life-history scenarios. Environ Toxicol Chem 16:1983-1989

Caswell H (1989) Analysis of life table response experiments. I. Decomposition of effects on population growth rate. Ecol Model 46:221-237

Caswell H (1996) Analysis of life table response experiments. II. Alternative parameterizations for size- and age-structured models. Ecol Model 88:73-82

Chareonpanich C, Montani S, Tsutsumi H, Matsuoka S (1993) Modification of chemical characters of organically enriched sediment by Capitella sp. I. Mar Pollut Bull 26: 375-379

Chareonpanich C, Tsutsumi H, Montani S (1994) Efficiency of the composition of organic matter, loaded on the sediment, as a result of the biological activity of Capitella sp. I. Mar Pollut Bull 28:314-318

Dando PR, Hughes JA, Thiermann F (1995) Preliminary observations on biological communities at shallow hydrothermal vents in the Aegean Sea. In: Parson LM, Walker CL, Dixon DR (eds) Hydrothermal vents and processes. Geological Society, London, p 303-317 (Spec Publ No. 87)

Eckelbarger KJ, Grassle JP (1983) Ultrastructural differences in the eggs and ovarian follicle cells of Capitella (Polychaeta) sibling species. Biol Bull 165:379-393

Eckelbarger KJ, Grassle JP (1987) Interspecific variation in genital spine, sperm, and larval morphology in six sibling species of Capitella. Bull Biol Soc Wash 7:62-76
Forbes VE, Calow $\mathrm{P}$ (1999) Is the per capita rate of increase a good measure of population-level effects in ecotoxicology? Environ Toxicol Chem 18:1544-1556

Forbes TL, Forbes VE, Depledge MH (1994) Individual physiological responses to environmental hypoxia and organic enrichment: implications for early soft-bottom community succession. J Mar Res 52:1081-1100

Forbes VE, Forbes TL, Holmer M (1996) Inducible metabolism of fluoranthene by the opportunistic polychaete Capitella sp. I. Mar Ecol Prog Ser 132:63-70

Gamenick I, Giere O (1994) Population dynamics and ecophysiology of Capitella capitata from North Sea intertidal flats. Evidence for two sibling species. Polychaete Res 16: $44-47$

Gamenick I, Abbiati M, Giere O (1998a) Field distribution and sulphide tolerance of Capitella capitata (Annelida: Polychaeta) around shallow water hydrothermal vents off Milos (Aegean Sea). A new sibling species? Mar Biol 130: $447-453$

Gamenick I, Vismann B, Grieshaber MK, Giere O (1998b) Ecophysiological differentiation of Capitella capitata (Polychaeta). Sibling species from different sulfidic habitats. Mar Ecol Prog Ser 175:155-166

Gardner WS, Lee RF, Tenore KR, Smith LW (1979) Degradation of selected polycyclic aromatic hydrocarbons in coastal sediments: importance of microbes and polychaete worms. Water Air Soil Pollut 11:339-347

Grant A (1998) Population consequences of chronic toxicity: incorporating density dependence into the analysis of life table response experiments. Ecol Model 105:325-335

Grassle JP, Butman CA (1989) Active habitat selection by larvae of the polychaetes, Capitella spp. I and II, in a laboratory flume. In: Ryland JS, Tyler PA (eds) Reproduction, genetics and distribution of marine organisms. Proc 23rd Euro Mar Biol Symp, Olsen \& Olsen, Fredensborg, p 107-114

Grassle JF, Grassle JP (1974) Opportunistic life histories and genetic systems in marine benthic polychaetes. J Mar Res 32:253-284

Grassle JP, Grassle JF (1976) Sibling species in the marine pollution indicator Capitella (Polychaeta). Science 192: 567-569

Grassle JP, Gelfman CE, Mills SW (1987) Karyotypes of Capitella sibling species, and of several species in the related genera Capitellides and Capitomastus (Polychaeta). Bull Biol Soc Wash 7:77-88

Hansen FT, Forbes VE, Forbes TL (1999) The effects of chronic exposure to 4-n-nonylphenol on life-history traits and population dynamics of the polychaete Capitella sp. I. Ecol Appl 9:482-495

Kammenga JE, Busschers M, Van Straalen NM, Jepson PC, Bakker J (1996) Stress induced fitness reduction is not determined by the most sensitive life-cycle trait. Funct Ecol 10:106-111

Kelley I, Freeman JP, Evans FE, Cerniglia CE (1993) Identification of metabolites from the degradation of fluoranthene by Mycobacterium sp. strain PYR-1. Appl Environ Microbiol 59(3):800-806

Kooijman SALM (1985) Toxicity at population level. In: Cairns $\mathrm{J}$ Jr (ed) Multispecies toxicity testing. Pergamon Press, New York, p 143-164

Levin LA, Caswell H, DePatra KD, Creed EL (1987) Demographic consequences of larval development mode: planktotrophy vs. lecitotrophy in Streblospio benedicti. Ecology 68:1877-1886

Levin LA, Caswell H, Bridges T, DiBacco C, Cabrera D, Plaia G (1996) Demographic responses of estuarine polychaetes 
to pollutants: life table response experiments. Ecol Appl 6:1295-1313

Linke-Gamenick I, Forbes VE, Sibly RM (1999) Densitydependent effects of a toxicant on life-history traits and population dynamics of a capitellid polychaete. Mar Ecol Prog Ser 184:139-148

Linke-Gamenick I, Vismann B, Forbes VE (2000) Effects of fluoranthene and ambient oxygen levels on survival and metabolism in three sibling species of Capitella (Polychaeta). Mar Ecol Prog Ser 194:169-177

Madsen SD, Forbes TL, Forbes VE (1997) Particle mixing by the polychaete Capitella species 1: coupling fate and effect of a particle-bound organic contaminant (fluoranthene) in a marine sediment. Mar Ecol Prog Ser 147: 129-142

McGill R, Tukey JW, Larsen WA (1978) Variations of box plots. Am Stat 32:12-16

Méndez N, Romero J, Flos J (1997) Population dynamics and production of the polychaete Capitella capitata in the littoral zone of Barcelona (Spain, NW Mediterranean). J Exp Mar Biol Ecol 218:263-284

Editorial responsibility: Otto Kinne (Editor),

Oldendorf/Luhe, Germany
Pearson M, Pearson TH (1991) Variation in populations of Capitella capitata (Fabricius, 1780) (Polychaeta) from the west coast of Scotland. Ophelia 5(Suppl):363-370

Pearson TH, Rosenberg R (1978) Macrobenthic succession in relation to organic enrichment and pollution of the marine environment. Oceanogr Mar Biol Annu Rev 16:229-311

Pechenik JA, Cerulli TR (1991) Influence of delayed metamorphosis on survival, growth, and reproduction of the marine polychaete Capitella sp. I. J Exp Mar Biol Ecol 151: $17-27$

Sibly RM (1999) Efficient experimental designs for studying stress and population density in animal populations. Ecol Appl 9:496-503

Thiermann F, Akoumianaki J, Hughes A, Giere O (1997) Benthic fauna of a shallow water gaseohydrothermal vent area in the Aegean sea (Milos/Greece). Mar Biol 128: 149-159

Wu BL, Qian PY, Zhang SL (1991) Morphology, reproduction, ecology and allozyme electrophoresis of three Capitella sibling species in Qingdao (Polychaeta: Capitellidae). Ophelia 5(Suppl):391-400

Submitted: December 21, 1999; Accepted: March 16, 2000

Proofs received from author(s): July 18, 2000 